\title{
Clinical Practice Informs Secure Messaging Benefits and Best Practices
}

Jolie N. Haun ${ }^{1,2}$ Wendy Hathaway ${ }^{1}$ Margeaux Chavez ${ }^{1}$ Nicole Antinori ${ }^{1}$ Brian Vetter ${ }^{3}$ Brian K. Miller ${ }^{4}$ Tracey L. Martin ${ }^{5}$ Lisa Kendziora ${ }^{6} \quad$ Kim M. Nazi $^{7} \quad$ Christine Melillo $^{1}$

${ }^{1}$ HSR\&D Center of Innovation on Disability and Rehabilitation Research, James A. Haley VA Hospital, Tampa, Florida, United States

${ }^{2}$ Department of Community and Family Health, University of South Florida College of Public Health, Tampa, Florida, United States

${ }^{3}$ Department of Veterans Affairs, St. Cloud VA Medical Center, St. Cloud, Minnesota, United States

${ }^{4}$ Northwest Innovation Center, VA Portland Health Care System, Portland, Oregon, United States

${ }^{5}$ Department of Veterans Affairs, VA New England Health Care System, Bedford, Massachusetts, United States

${ }^{6}$ Department of Veterans Affairs, Erie VA Medical Center, Erie, Pennsylvania, United States

7 Veterans and Consumers Health Informatics Office, Veterans Health Administration, Department of Veterans Affairs, Washington, District of Columbia, United States

Appl Clin Inform 2017;8:1003-1011.
Address for correspondence Jolie N. Haun, PhD, EdS, HSR\&D Center of Innovation on Disability and Rehabilitation Research, 8900 Grand Oaks Circle, Tampa, FL 33637, United States

(e-mail: Jolie.Haun@va.gov).

\section{Abstract}

Keywords

- patient provider communication

- messaging

- ambulatory care/ primary care

- process improvement

- diffusion of innovation
Background Clinical care team members in Department of Veterans' Affairs (VA) facilities nationwide are working to integrate the use of Secure Messaging (SM) into care delivery and identify innovative uses. Identifying best practices for proactive use of SM is a key factor in its successful implementation and sustained use by VA clinical care team members and veterans.

Objectives A collaborative project solicited input from VA clinical care teams about their local practices using SM to provide access to proactive patient-centered care for veterans and enhance workflow.

Methods This project implemented a single-item cross-sectional qualitative electronic survey via internal e-mail to local coordinators in all 23 Veterans Integrated Service Networks (VISNs). Content analysis was used to manage descriptive data responses. Descriptive statistics described sample characteristics.

Results VA clinical care team members across 15 of 23 VISNs responded to the questionnaire. Content analysis of 171 responses produced two global domains: (1) benefits of SM and (2) SM best practices. Benefits of SM use emphasize enhanced and efficient communication and increased access to care. Care team members incorporate SM into their daily clinical practices, using it to provide services before, during, and after clinical encounters as a best practice. SM users suggest improvements in veteran care, clinical team workflow, and efficient use of health resources. Clinical team members invested in the successful implementation of SM integrate SM into their daily practices to provide meaningful and useful veteran-centered care and improve workflow. received

June 1, 2017

accepted after revision

August 15, 2017
Copyright @ 2017 Schattauer
DOI https://doi.org/ 10.4338/ACI-2017-05-RA0088 .

ISSN 1869-0327. 
Conclusion VA clinical care team members can use SM proactively to create an integrated SM culture. With adequate knowledge and motivation to proactively use this technology, all clinical team members within the VA system can replicate best practices shared by other clinical care teams to generate meaningful and useful interactions with SM to enrich veterans' health care experience.

\section{Background and Significance}

Secure Messaging (SM) is an asynchronous communication tool within the Department of Veterans' Affairs (VA) My HealtheVet (MHV) patient portal. Similar to e-mail, SM provides a convenient and secure way for veterans to communicate electronically with their VA health care teams and other VA staff. Implementation of SM began on a voluntary basis in 2008; however, by 2012 it became mandatory for all VA primary care teams to ensure nationwide availability for veterans to communicate electronically with their primary care teams. Teams can establish a triage process for incoming messages that aligns with their existing processes (e.g., a nurse may triage and respond and complete or assign an incoming message from a veteran to a specific staff member). Based on guidelines for appropriate use for delivery of care and communication with veteran patients, SMs from veterans must be responded to and completed within 3 business days or the message is escalated and alerts are generated to notify the team. SMs may be reassigned not only to other team members but also to other SM teams both locally and nationally. SMs may be saved to the patient's electronic record as necessary to keep all care providers informed and, as appropriate, documented as an online evaluation and management encounter.

SM is an effective tool for supporting patient access to care and enhancing patient-provider communication, patient engagement, and self-management. This is accomplished through more efficient utilization of health services and resources, resulting in improved patient outcomes. ${ }^{1-12}$ To this end, VA has established MHV coordinators throughout the VA health care system to enroll patients and support their use of this patient-facing portal. A national My HealtheVet Coordinator Workgroup prioritizes goals related to enrollment, use, and functioning of SM across the VA health care system. The workgroup includes subject matter experts, operational partners, and local MHV coordinators. A systematic literature review conducted by VA researchers suggests that use of a patient portal including SM was associated with improved patient satisfaction and improved outcomes for patients with chronic diseases including diabetes and hypertension. ${ }^{13}$ A VA study conducted by Shimada et al demonstrated that sustained use of SM improved glycemic control and LDL (low-density lipoprotein) cholesterol for patients with type 2 diabetes mellitus. ${ }^{14}$ These studies suggest that use of SM as part of an integrated patient portal results in improved patient satisfaction, compliance, and communication, yielding improved patient outcomes. However, as with most innovations in health care, there is variation in perceived value and use. To date, most SMs are initiated by veterans, with the health care team responding to questions or requests. Yet the potential for SM to be used proactively, with the health care team initiating a message to the patient, may provide additional benefits. Further expansion to all surgical and specialty care teams has been significant; however, not all potential users (i.e., clinical care team members) are fully invested, motivated, or aware of how to fully integrate SM into care delivery. Identifying and disseminating local best practices for innovative and proactive use of SM is a key factor in its successful implementation and sustained use by VA clinical care team members and veterans to generate meaningful and useful interactions with SM.

\section{Objectives}

The goal of this project was to improve the integration of SM into the fabric of VA health care by identifying and disseminating SM best practices reported by front-line VA clinical care team members to provide proactive, patient-centered care to veterans and enhance provider workflow.

\section{Methods}

The VHA system is divided into 23 network areas called Veterans Integrated Service Networks (VISNs). This fieldinitiated collaborative project used a cross-sectional study design to distribute a single-item electronic survey via internal e-mail to local MHV coordinators in all 23 VISNs. MHV coordinators used e-mail and interpersonal contact to solicit input from their local clinical communities. Individual methods used by coordinators were not collected as part of this data collection process.

As a part of the operational mission of the VA to increase the proactive use of SM by clinical care team members, survey findings were disseminated using multiple methods. VA leverages multiple strategies for informing, educating, and motivating adoption of best practices by VA employees and as such the research team, operational representatives, and the national My HealtheVet Coordinator Workgroup collaborated to create a series of products for dissemination including a multimedia video and a 'playbook' of best practices. These products were disseminated on a series of leadership calls, distributed to national workgroups, and posted on internal shared sites to be accessible to all VA employees. These dissemination efforts are further detailed in the discussion section. 


\section{Data Collection Instrument}

A single-item questionnaire was developed to elicit information about how front-line providers use SM to: (1) improve communication; (2) improve efficiency; (3) increase patient access; and (4) improve workflow in clinical practice. These four areas are key priorities to the MHV Workgroup. Providers were specifically asked: "Please explain how you are using Secure Messaging to improve communication, efficiency, patient access, or workflow in your practice." Open-ended responses were collected to encourage clinical care teams to think broadly and describe their practices in their own words.

\section{Data Management and Security}

Responses were organized by row using an Excel spreadsheet. Responses were de-identified, assigned unique response IDs and entered in individual cells. Corresponding cells in each response row contained respondent demographic information that included the Respondent's Role, VISNs, Medical Center, and Service Unit. The spreadsheet was housed on a server protected by the VA firewall and raw data were shared using encrypted e-mail only.

\section{Data Analysis}

A rapid, content analysis of responses was conducted by two trained qualitative researchers. Researchers created a data reduction matrix ${ }^{15}$ using a Microsoft Excel workbook to organize response data by domains and subdomains that represented clinical care team member's experiences using SM. First-level coding was guided by the four domains stated in the single-item questionnaire. Data were organized into descriptive titles representing the four primary questionnaire constructs: (1) communication, (2) efficiency, (3) patient access, and (4) workflow improvements. Constructs were not mutually exclusive and could be single-, double-, triple-, or quadruple-coded to account for multiple topics within a single entry. For example, a response could be coded "efficiency" and "communication" if it indicated that using SM to follow up with patients instead of calling them on the phone saves time and creates a record of contact that the patients can review as many times as they need. Responses were then sorted into four separate spreadsheets representing each of the four constructs. The sorted spreadsheet responses were coded using a second-level, thematic coding technique, which drilled down on subdomains within each domain. Researchers used memos to describe and operationalize codes and document their decision-making process. Memos helped researchers refine subdomains iteratively during the coding process. Following thematic coding, all data were sorted into two global domains: (1) benefits of SM and (2) SM best practices.

Finally, a panel of subject matter experts from the MHV Coordinators Workgroup and VA national offices reviewed and validated data findings. A total of nine review sessions were conducted over 2 months to validate data and reach agreement. The dataset collected for the current study are available from the corresponding author on reasonable request; however, the majority of data generated during this study are included in this published article as - Supplementary Material (available in the online version).
Table 1 VA service and respondent role frequencies and percentages

\begin{tabular}{|c|c|}
\hline & $N(\%)$ \\
\hline \multicolumn{2}{|l|}{ VA service } \\
\hline Primary care & 85 (49.7) \\
\hline Specialty care & $61(35.7)$ \\
\hline Behavioral health & $16(9.4)$ \\
\hline $\begin{array}{l}\text { Health promotion and } \\
\text { disease prevention }\end{array}$ & $6(3.4)$ \\
\hline Women's health & $3(1.8)$ \\
\hline \multicolumn{2}{|l|}{ VA respondent role } \\
\hline Nursing & $55(32.2)$ \\
\hline Provider & $37(21.6)$ \\
\hline LCSW & $3(1.8)$ \\
\hline MHV coordinator & $3(1.8)$ \\
\hline PM\&R & $1(0.6)$ \\
\hline Psychologist & $4(2.3)$ \\
\hline Other & 34 (19.9) \\
\hline Missing & 34 (19.9) \\
\hline
\end{tabular}

Abbreviations: LCSW, licensed clinical social worker; MHV, My HealtheVet; PM\&R, physical medicine and rehabilitation.

\section{Results}

One hundred and seventy-one responses to the survey item were collected from clinical care team members representing 15 of the 23 VISNs. Clinical care team type of VA service, respondent role, and geographic VISNs are shown in - Table 1. Responses represented two global domains: (1) benefits of SM and (2) SM best practices. A comprehensive list of responses is organized in -Supplementary Material (available in the online version).

Clinical care team member reports addressed access, trust, quality and continuity of communication, and care. Team members reported SM enhances continuity in communication among care team members and veterans. SM increases access to communicate with veterans, while simultaneously providing a multitude of workflow benefits; limiting duplication of efforts, and increasing efficient use of time and resources (e.g., paper, labels, postage). Team members also reported a perceived reduction in miscommunication and related errors. Efficiency in response times and reductions in miscommunications and errors all contribute to a key benefit of improving veteran's access to care and their experience of care and reducing their frustration to ensure high-quality service delivery. Domains and exemplar quotes relevant to clinical team members-identified benefits of SM are presented in - Table 2 .

Most notable in this dataset, clinical care team member reports identified best practices that benefitted both veterans and clinical care teams. Reported best practices were related to creating an SM culture. SM culture is best defined as the standard by which meaningful use of SM is fully integrated throughout the process of health care delivery. 
Table 2 Subdomains and exemplar quotes for benefits of Secure Messaging from perspective of clinical care members

\begin{tabular}{|c|c|c|}
\hline Benefits & Exemplar quotes & \# \\
\hline $\begin{array}{l}\text { 1. SM enhances communica- } \\
\text { tion among providers and } \\
\text { between providers and } \\
\text { veterans }\end{array}$ & $\begin{array}{l}\text { Secure Messaging has been a method that has allowed me to engage the veteran } \\
\text { in his health care, educate him on his disease state, and allow him the power to } \\
\text { be in control of his situation. It also helps to ease some of the stress in his family } \\
\text { as his wife no longer has to be an "in-between" for clinical recommendations. } \\
\text { Improved communication has also been significantly improved as there have } \\
\text { recently been many challenges that veterans perceive with the telephone system } \\
\text { that is currently used. }\end{array}$ & 32 \\
\hline \multirow{2}{*}{$\begin{array}{l}\text { 2. SM allows providers to } \\
\text { have a broad reach. } \\
\text { They can reach a mass of } \\
\text { patients with one e-mail } \\
\text { versus sending multiple } \\
\text { e-mails }\end{array}$} & $\begin{array}{l}\text { I can reach hundreds of veterans with the click of a button. I am also able to reach } \\
\text { veterans who may not come to the VA as often as others so they know my group } \\
\text { is being offered. }\end{array}$ & \multirow[t]{2}{*}{10} \\
\hline & $\begin{array}{l}\text { I can send out all five messages to participants in } \sim 15-30 \text { minutes. So, with } \\
\text { minimal time spent, veterans have access to a great deal of useful information } \\
\text { that enhances our class content. }\end{array}$ & \\
\hline \multirow[t]{2}{*}{$\begin{array}{l}\text { 3. SM saves resources. (e.g., } \\
\text { paper, labels, postage) }\end{array}$} & $\begin{array}{l}\text { Sending some content electronically saves paper. The veterans can print it out if } \\
\text { they think it would be useful and add it to their binder. We also provide clickable } \\
\text { links and other web-based resources that are less effective when printed out. }\end{array}$ & \multirow[t]{2}{*}{6} \\
\hline & $\begin{array}{l}\text { Using SM has saved me a lot of time that I would have spent making labels and } \\
\text { mailing out the information. }\end{array}$ & \\
\hline \multirow[t]{2}{*}{$\begin{array}{l}\text { 4. SM reduces miscommuni- } \\
\text { cations and related errors }\end{array}$} & $\begin{array}{l}\text { Facilitates a real-time exchange of health information and therefore decreases } \\
\text { medical mishaps due to miscommunication. }\end{array}$ & \multirow[t]{2}{*}{11} \\
\hline & I communicate with them directly, eliminating the risk of miscommunication. & \\
\hline $\begin{array}{l}\text { 5. SM increases provider } \\
\text { efficiency and limits veteran } \\
\text { frustration because it saves } \\
\text { time and limits duplication } \\
\text { efforts }\end{array}$ & $\begin{array}{l}\text { Our PACT has utilized SM to quickly communicate with our patients. Veterans are } \\
\text { comfortable sending messages at their leisure and our response time is very fast. } \\
\text { This saves time for both the PACT and the veteran. Many patients prefer this over } \\
\text { calling on the telephone. }\end{array}$ & 30 \\
\hline \multirow[t]{2}{*}{$\begin{array}{l}\text { 6. SM improves patients' } \\
\text { access to health care }\end{array}$} & $\begin{array}{l}\text { I use SM to: receive queries from the patients; answer patient concerns in a } \\
\text { timely manner; receive and respond to medication renewals and changes; triage } \\
\text { some symptoms; notify patients about their test results; improve patient access } \\
\text { by offering same day appointments, etc. }\end{array}$ & \multirow[t]{2}{*}{51} \\
\hline & $\begin{array}{l}\text { Our veterans know they can use this communication tool instead of the } \\
\text { telephone, walking into the clinic and/or emergency room while knowing their } \\
\text { needs will be met expeditiously. }\end{array}$ & \\
\hline \multirow{2}{*}{$\begin{array}{l}\text { 7. SM establishes trust and } \\
\text { improves consumer } \\
\text { confidence in the VA } \\
\text { system }\end{array}$} & Build-up patients' confidence that the doctor and team are only an SM away. & \multirow[t]{2}{*}{13} \\
\hline & $\begin{array}{l}\text { I use SM to provide the veteran with a direct connection to the PACT-this allows } \\
\text { the user to have more control of his care, it allows the staff to provide the veteran } \\
\text { with outstanding service, it reduces the run around effect other veterans } \\
\text { experience due to not using the service, and this practice reassures the veteran } \\
\text { that his needs are being heard and met. }\end{array}$ & \\
\hline $\begin{array}{l}\text { 8. SM ensures quality service } \\
\text { delivery }\end{array}$ & $\begin{array}{l}\text { Veterans concerns are carefully considered by the licensed practical nurse, } \\
\text { registered nurse, and finally the physician, which improves the quality of care we } \\
\text { provide. }\end{array}$ & 5 \\
\hline
\end{tabular}

Creating an effective SM culture is critical for effective and sustained implementation because accepted and expected SM use is a cultural standard by user groups in delivering and receiving health care.

Responses indicate creating a positive SM culture is an assimilation of proactively educating staff about SM and endorsing its proactive use, asking staff to prioritize SM enrollment, integrating SM into daily clinical practice, using SM for proactive outreach, leveraging SM across VA services, and integrating SM into their current workflow. Respondents described the most effective practices for integrating SM into provider's workflow or "triaging." These include: establishing SM responsibilities by clinical role; requiring that clinical care team members designate protected time to review and respond to SM; using SM to follow up after a visit or missed appointment; using SM for preappointment preparation; and responding to SMs within 24 hours. Two other subdomains that emerged from the data were practices of managing population health and reflecting on correspondence to promote patient-centered tone and language. Subdomains and exemplar quotes relevant to clinical team members-identified SM best practices are presented in -Table 3 . 
Table 3 Subdomains and exemplar quotes for Secure Messaging best practices

\begin{tabular}{|c|c|c|}
\hline Best practices & Exemplar quotes & $\#$ \\
\hline \multicolumn{3}{|c|}{ Providers create a proactive, integrated SM culture by: } \\
\hline $\begin{array}{l}\text { 1. Proactively educating } \\
\text { staff and patients about } \\
\text { SM }\end{array}$ & $\begin{array}{l}\text { The nurse enrolls/authenticates veterans into SM. The provider never lets a } \\
\text { veteran leave the clinic without suggesting SM. Team members always } \\
\text { respond to employee/veteran questions. Veterans are encouraged to use SM } \\
\text { and are told to expect a response from us in a timely manner. We are able to } \\
\text { build their trust by doing just that. Market the tool unceasingly (increases } \\
\text { enrollment); teach/explain how to use the tool at the veteran's level; stress } \\
\text { the benefits of the tool to all veterans, even the veterans currently enrolled; } \\
\text { answer/follow up with veterans as soon as possible. }\end{array}$ & 10 \\
\hline \multirow[t]{2}{*}{$\begin{array}{l}\text { 2. Integrating SM } \\
\text { enrollment process }\end{array}$} & $\begin{array}{l}\text { Upon admission to the Home Telehealth program, SM is presented. Benefits } \\
\text { are explained and patients encouraged to sign up }\end{array}$ & \multirow[t]{2}{*}{8} \\
\hline & $\begin{array}{l}\text { Currently, when the patients check in for their appointments during the } \\
\text { screening process, the registered nurse or licensed practical nurse educates } \\
\text { the veteran about MHV and gives them a pamphlet regarding the services } \\
\text { provided. When the veteran is checking out, the clerk at the front desk then } \\
\text { directs the veteran to the second floor where the MHV kiosk and authenti- } \\
\text { cation center is located. The nurse on our team has been trained to } \\
\text { authenticate the users (TMS Training and One and One training by the MHV } \\
\text { coordinator). She prints out the list of veterans who have appointments for } \\
\text { the week that need to be authenticated, and when the veterans come in for } \\
\text { their appointments, they are authenticated in person. Then they are in- } \\
\text { structed to send their PACT a test message. This process is done for all five } \\
\text { PACT members located in the clinic. }\end{array}$ & \\
\hline $\begin{array}{l}\text { 3. Integrating SM into daily } \\
\text { practice }\end{array}$ & $\begin{array}{l}\text { My daily practice is to check SM upon logging onto my computer first thing at } \\
\text { the start of my shift every day. I answer all my veterans even if it is only to tell } \\
\text { them I need to find the answer to their questions and then I will be back in } \\
\text { touch. I encourage all my veterans to use SM to contact me and assure them if I } \\
\text { am on duty they will hear from me quickly. I sometimes have conversations } \\
\text { with my veterans almost in real time. They love having direct access to the } \\
\text { nurse. My practice is simple yet highly effective. I make SM users a priority } \\
\text { during my daily work. }\end{array}$ & 8 \\
\hline $\begin{array}{l}\text { 4. Endorsing proactive } \\
\text { SM use }\end{array}$ & $\begin{array}{l}\text { The PACT encourages and trains the patient on how and when to use SM. For } \\
\text { example: be proactive and make a request for prescription renewal before } \\
\text { they run out. If patients are not finding improvement on a current problem, } \\
\text { they are encouraged to update us so we can quickly follow up. Patients can } \\
\text { check up on status of outside paper work needing to be filled out by their } \\
\text { provider. Patient can alert provider of a recent unplanned hospital visit which } \\
\text { can expedite follow-up paperwork that may be required. Consults can be } \\
\text { placed with proper follow-up by team; they may require a provider visit or just } \\
\text { simply need one entered. This helps with patient access. }\end{array}$ & 9 \\
\hline 5. Proactive outreach & $\begin{array}{l}\text { The Bless Her Heart Campaign is part of a Whole-hearted Women Veterans } \\
\text { Initiative that was funded by VA Central Office in January } 2015 \text { by the } \\
\text { Women's Health Service. There are three components: (1) identify high-risk } \\
\text { women veterans for heart disease using CPRS parameters and laboratory data } \\
\text { in } 4,072 \text { women in primary care; ( } 2 \text { ) design new specific interventions (e.g., } \\
\text { tobacco, stress, diabetes, move) for "women veterans only" to raise aware- } \\
\text { ness of risks and offer medical center resources to help the veteran make } \\
\text { lifestyle changes; ( } 3 \text { ) complete a quality improvement assessment of all } \\
\text { women veterans who have been identified as having heart or vascular disease } \\
\text { ( } n=263 \text { ) in the problem list to verify accuracy and check for quality of care } \\
\text { from clinical practice guidelines. All women who are contacted are encour- } \\
\text { aged to be enrolled in MHV and complete their HealtheLiving Assessment } \\
\text { which we enter into our database with their permission. We also complete a } \\
\text { risk estimate online for arteriosclerotic cardiovascular disease using the } \\
\text { American College of Cardiology/American Heart Association heart risk for- } \\
\text { mula for each woman. We have passed out arteriosclerotic cardiovascular } \\
\text { disease risk checklist handouts about heart disease to all women veterans and } \\
\text { women employees on "Wear Red Day" on the first February. We are now } \\
\text { developing an SM group just for our Bless Her Heart Campaign where all } \\
\text { women veterans can communicate directly with our nurse care manager and } \\
\text { providers about their progress. }\end{array}$ & 6 \\
\hline
\end{tabular}


Table 3 (Continued)

\begin{tabular}{|c|c|c|}
\hline Best practices & Exemplar quotes & \# \\
\hline \multirow[t]{2}{*}{$\begin{array}{l}\text { 6. Acknowledging that SM } \\
\text { crosses all VA services }\end{array}$} & $\begin{array}{l}\text { As a vocational rehab counselor, I use SM to share job leads with veterans and } \\
\text { communicate back and forth regarding resume revisions. The SM attachment } \\
\text { feature has saved many veterans trips to the VA to revise resumes and has } \\
\text { greatly enhanced our ability to make veterans aware of job opportunities. }\end{array}$ & \multirow[t]{2}{*}{4} \\
\hline & $\begin{array}{l}\text { As a speech pathologist, we provide education and rehabilitation on com- } \\
\text { munication and cognitive skills. I incorporate SM training into sessions with } \\
\text { veterans to ensure they have access to their providers when they need it. }\end{array}$ & \\
\hline \multicolumn{3}{|c|}{ 7. Integrating SM into providers' workflow } \\
\hline \multirow{2}{*}{$\begin{array}{l}\text { a. Establishing an SM } \\
\text { workflow or "triage" } \\
\text { plan and designating } \\
\text { staff to complete spe- } \\
\text { cific responsibilities } \\
\text { within the plan }\end{array}$} & $\begin{array}{l}\text { I like how the messages are assigned to the members of our PACT depending } \\
\text { on what the needs of the veteran are. That way we work together as a TEAM to } \\
\text { take care of our veterans. }\end{array}$ & \multirow[t]{2}{*}{18} \\
\hline & $\begin{array}{l}\text { I use SM to: receive queries from the patients; answer patient concerns in a } \\
\text { timely manner; receive and respond to medication renewals and changes; } \\
\text { triage some symptoms; notify patients about their test results; improve } \\
\text { patient access by offering same day appointments, since it is a quick and } \\
\text { efficient way to contact patients; reduce the number of unnecessary emer- } \\
\text { gency room visits by effectively communicating with the patients; address } \\
\text { necessary test orders prior to follow-ups to improve workflow; and reduce the } \\
\text { number of phone calls. }\end{array}$ & \\
\hline $\begin{array}{l}\text { b. Establishing a time } \\
\text { frame each day within } \\
\text { which providers check } \\
\text { and respond to SMs }\end{array}$ & $\begin{array}{l}\text { Messages are answered on a daily basis and able to provide some response to } \\
\text { the veteran the same day. Secure Messaging eliminates "phone tag" and the } \\
\text { veterans reply at their convenience. }\end{array}$ & 10 \\
\hline $\begin{array}{l}\text { c. Responding to SMs } \\
\text { within } 24 \text { hours to at } \\
\text { least acknowledge } \\
\text { receipt of } \\
\text { communication }\end{array}$ & $\begin{array}{l}\text { The veterans are able to send us messages and we respond to their request } \\
\text { usually within } 12-24 \text { hours. Most of our narcotic patients have signed up for } \\
\text { SM as part of their treatment plan. }\end{array}$ & 6 \\
\hline \multirow[t]{2}{*}{$\begin{array}{l}\text { d. Follow-ups after visit } \\
\text { or to missed } \\
\text { appointment }\end{array}$} & $\begin{array}{l}\text { Not only do I utilize SM to reply to patients' messages, but I also use it to } \\
\text { initiate conversations. I notify the patients via SM regarding orders, ap- } \\
\text { pointments, test results (if normal), and follow-up with them after a change in } \\
\text { medication or after a procedure. }\end{array}$ & \multirow[t]{2}{*}{18} \\
\hline & When a veteran fails to show up for an appointment, I can use SM to contact him. & \\
\hline $\begin{array}{l}\text { e. Preappointment } \\
\text { preparation }\end{array}$ & $\begin{array}{l}\text { I work in mental health, and one patient in particular (a complex patient with } \\
\text { posttraumatic stress disorder and traumatic brain injury) uses SM to write out } \\
\text { his thoughts and feelings to process between sessions. This saves time in } \\
\text { session as there is less for him to have to remember and try to formulate in } \\
\text { session. It also allows him a tangible way to "work" between sessions and } \\
\text { encourages him to process all that he is feeling and thinking. }\end{array}$ & 13 \\
\hline \multirow[t]{4}{*}{$\begin{array}{l}\text { 8. Managing population } \\
\text { health }\end{array}$} & $\begin{array}{l}\text { Secure Messaging is a tool for population health management. For example, } \\
\text { reaching out to patients from our Flu Registry who do not have a documented } \\
\text { flu vaccine for information on whether they received one or would like to } \\
\text { come in to be vaccinated. }\end{array}$ & \multirow[t]{4}{*}{5} \\
\hline & $\begin{array}{l}\text { In Health Promotion and Disease Prevention, SM is used for ongoing weight } \\
\text { management and nutrition care. Veterans can participate in ongoing follow- } \\
\text { up, and share their successes, questions, issues related to these via SM. }\end{array}$ & \\
\hline & $\begin{array}{l}\text { I use PACT distribution groups to send SM to announce our "Healthier Living } \\
\text { with Chronic Conditions" workshops. We offer these only periodically and do } \\
\text { not have a formal consult for this reason. Secure Messaging has worked great } \\
\text { to fill the workshops with veterans who are interested and motivated to } \\
\text { improve their health and self-management abilities. }\end{array}$ & \\
\hline & $\begin{array}{l}\text { Infectious processes in one patient can place other patients and their } \\
\text { providers at risk. Secure Messaging enables me to share important informa- } \\
\text { tion securely and timely with our entire health care team. Secure Messaging } \\
\text { also enables providers, laboratory personnel, therapist, etc., to utilize me as } \\
\text { an assist in obtaining research materials, public health information, or data } \\
\text { they may need. Quick communication is one of the tools that I, as an Infection } \\
\text { Preventionist, use to help stop the spread of communicable diseases. }\end{array}$ & \\
\hline
\end{tabular}




\begin{tabular}{|c|c|c|}
\hline Best practices & Exemplar quotes & $\#$ \\
\hline \multirow[t]{2}{*}{$\begin{array}{l}\text { 9. Reflecting on their } \\
\text { correspondence; they } \\
\text { can communicate tone } \\
\text { and language that is } \\
\text { patient centered }\end{array}$} & $\begin{array}{l}\text { Lastly, I am very careful of the tone and language in my SM to patients. I want } \\
\text { to express understanding and the idea that the provider-patient relationship } \\
\text { can still be empathic through a virtual modality. I often end with words like } \\
\text { "Thank you for reaching out," "Please let me know if you have any more } \\
\text { questions," "Look forward to seeing you at your next visit on } \\
\text { these "touch" phrases are important and can be another way to express } \\
\text { patient centeredness. }\end{array}$ & \multirow[t]{2}{*}{3} \\
\hline & $\begin{array}{l}\text { For most patients, I have found that they comprehend the messages better when } \\
\text { they can read it and then review it later. I have also found that when a patient is } \\
\text { called and provided a message, the message can be misunderstood, which can } \\
\text { lead to several returned telephone calls. By being able to go back and review the } \\
\text { message, they can usually answer any questions that may come up on their own, } \\
\text { which allows another veteran to be taken care of during that time slot. }\end{array}$ & \\
\hline
\end{tabular}

\section{Discussion}

As part of an organization-wide initiative to integrate SM into VA care delivery, this project was designed to solicit input directly from front-line VA clinical care teams to identify benefits and best practices related to using SM. The overall goal was to disseminate these findings nationally to demonstrate how VA clinical care teams can use SM in a useful and meaningful way to support proactive veteran-centered care and enhance clinical workflow. This article leverages the experiences of this user group to give insight into their SM experience to inform a peer-driven approach to innovation implementation and adoption, by tapping into the practices of motivated users who perceived benefits from their experience using SM. The purpose of this project was to seek insights about the meaningful use of SM by front-line clinicians and staff to inform efforts to promote its sustained proactive meaningful use nationally across all clinical care teams. As such, the quantity of responses is not as meaningful as the quality of the responses. A benefit and/or best practice does not need to be reported multiple times to be meaningful and/or innovative.

First, data indicate clinical care team member respondents perceived several benefits to using SM. When compared with previous data collected from veterans, ${ }^{16,17}$ about their perceived benefits associated with SM use, these clinical narratives mirror that SM enhances access, trust, quality, and continuity and illustrated a multitude of workflow benefits including efficient use of time and resources. Beyond benefits, the core objective of this project was to identify and disseminate best practices which would demonstrate the usefulness of SM. The most compelling practice was clinical care team members' use of SM proactively to create an integrated SM culture in which SM is viewed as an integral part of providing clinical care, no less important than taking a patient's blood pressure or writing a prescription. Clinical care teams created a culture of SM by integrating the use of this electronic communication tool into clinical practice and service provision before, at, and after the point of care. Proactively educating staff and enrolling patients, endorsing use among user groups, and integrating the tool into daily practice and workflow provided a multiprong approach to integrating this tool into the culture of care delivery.
Establishing this culture enhances provider buy-in, utilization, and promotion through communication.

SM represents a communication platform that can be used in varying ways by local clinical care teams. Using SM to manage population health is a critical example of the broad reach and efficiency this tool can provide, particularly to areas of specialty care such as health promotion and disease prevention, and infectious disease management. Finally, and maybe most notable, the practice of perceiving SM messages as correspondence can enhance communication by using patient-centered tone and language. Synchronous communication, such as face-to-face conversations and phone calls, does not allow for editing of tone and language, whereas SM, an asynchronous communication method, allows the sender to review and edit message content to ensure language is appropriate, supportive, and patient-centered. This surfaced as a best practice which can promote the vital and often unstated values of trust and high-quality communication among veterans and their health care team members. In a large system, with the potential for patients to feel lost and depersonalized, this practice promotes the personal touch of empathy, compassion, and respect that can be crucial in all forms of communication when delivering care to patients.

\section{Dissemination of Findings}

Several products were developed to support dissemination of these findings throughout the VA. Findings were distilled into a 7-minute educational video for national dissemination. This product was designed and produced with VA clinical team members to optimize relevance and usefulness. Survey responses were also used to create a "Secure Messaging Best Practices Playbook" as a companion reference piece to the SM Best Practices video. The "Secure Messaging Best Practices Playbook" provides the user with a comprehensive document that can be easily navigated to sections of the users' interest (- Supplementary Material, available in the online version). The video was published on VA's national MHV and SM workgroup web sites and disseminated to VA's national primary care, social work, patient advocate, dental, patient care services, caregiver support, and case manager networks. This content was also presented by VA Office of Connected Care leadership on a national MHV 
coordinator teleconference meeting. This work was also used to develop a chapter in the VA Undersecretary's book entitled, "Best Care Anywhere."

\section{Limitations}

The limitations of this project should be considered when interpreting these data. First, this is a convenience sample of VA staff; the representativeness and generalizability applies only to the VISNs and VA clinical care team members who responded. Nor do we have specific data on how local coordinators solicited responses to the survey item from clinical care team members. Second, there is threat for response bias. It should also be noted that this sample is heavily weighted toward the nursing perspective, but it also supports anecdotal reports that nursing staff are often the care team members communicating through SM. Additionally, data represented approximately $65 \%$ of VA VISNs with more than $53 \%$ of respondents from three VISNs; thus, ability to generalize findings to those underrepresented is limited. However, qualitative data responses are based on representation and saturation; as such, data findings present meaningful results for informing SM benefits and best practices. Third, as with any descriptive study that is cross-sectional in nature, the study does not allow statements on motivation for SM use. However, it does provide much needed descriptive data to understand clinical team members' experiences in using SM to deliver health care. Fourth, the generalizability of these findings outside the VA system, within private sector clinical care systems, is limited and does not account for economic incentives, which are different across these care settings. Finally, although this study provided important data on clinical care team members' experiences and perceptions about the use of SM, we cannot comment on how veterans' experience these reported practices. However, insight into veterans' experiences using SM has been explored by this research in previous studies. ${ }^{16,17}$

\section{Future Research}

Future research would benefit from this field of inquiry by addressing contextual facilitators and barriers to clinical team members' use of SM and interventions to overcome barriers. To enhance use of SM by care team members other than nursing (e.g., physicians, specialty care), future research should focus on provider experiences and needs, specifically targeting responses from these clinical roles for a more well-rounded perspective. Future implementation research should evaluate specific implementation strategies for promoting adoption and sustained integrated and meaningful use by clinical care teams, and determining if different groups respond to different implementation strategies. Additionally, future research should explore the appropriate use and effects of SM in care management and patient outcomes, and costs associated with the use of SM in care delivery.

\section{Conclusion}

SM represents a communication platform that can be used in many useful and meaningful ways by local clinical care teams. Soliciting input directly from local clinical care teams can be an effective strategy for identifying best practices that can then be further disseminated to encourage implementation of these practices throughout the national system. Local clinical care teams report that the proper use of SM can improve veterans' care and clinical team workflow, and support the efficient use of the VA's health resources. However, knowing how to effectively use the tool to deliver health care is a key factor in its sustained proficient use. Using actual clinical narratives to inform other VA providers about how to benefit from SM use is critical to improving provider uptake of the tool. Front-line providers have the credibility and contextual knowledge to describe acceptable and useful practices for integrating SM into their daily practice to provide veteran-centered care and improve workflow. With adequate knowledge and motivation, efforts to proactively use SM can be replicated by all clinical team members within the VA system.

\section{Clinical Relevance Statement}

VA clinical care team members can use SM proactively to create an integrated SM culture. Care team members generate this culture by incorporating SM into their clinical practices, using it to provide services before, at, and after clinical encounters. An integrated SM culture can support the efficient use of health resources, improve clinical team workflow, and foster excellence in veteran care.

\section{Multiple Choice Questions}

When creating a culture of Secure Messaging, which of the following must be considered?

A. Educating clinicians about benefits and best uses of Secure Messaging.

B. Educating veterans about benefits and best uses of Secure Messaging.

C. Promoting use of Secure Messaging by clinicians and veterans.

D. All of the above.

The correct answer is D. Educating clinicians and veterans about benefits and best uses of Secure Messaging and promoting their use of Secure Messaging is critical to supporting sustained meaningful use of Secure Messaging in delivering and receiving clinical care services.

Note

The contents of this article do not represent the views of the Department of Veterans' Affairs or the United States Government. All the authors have approved the final version of the article.

\section{Protection of Human and Animal Subjects}

Procedures were reviewed and are in compliance with ethical standards of the local institutional review board and with the World Medical Association Declaration of Helsinki on Ethical Principles for Medical Research Involving Human Subjects. 


\section{Funding}

None.

\section{Conflict of Interest}

None.

\section{Acknowledgments}

The development of this article was supported by the Department of Veterans' Affairs, Veterans Health Administration, and in part by the Center of Innovation for Disability and Rehabilitation Research at the James A. Haley Veterans Hospital and the Veterans and Consumers Health Informatics Office.

\section{References}

1 Nazi KM. The personal health record paradox: health care professionals' perspectives and the information ecology of personal health record systems in organizational and clinical settings. J Med Internet Res 2013;15(04):e70

2 Harris LT, Koepsell TD, Haneuse SJ, Martin DP, Ralston JD. Glycemic control associated with secure patient-provider messaging within a shared electronic medical record: a longitudinal analysis. Diabetes Care 2013;36(09):2726-2733

3 Ye J, Rust G, Fry-Johnson Y, Strothers H. E-mail in patient-provider communication: a systematic review. Patient Educ Couns 2010; 80(02):266-273

4 Roter DL, Larson S, Sands DZ, Ford DE, Houston T. Can e-mail messages between patients and physicians be patient-centered? Health Commun 2008;23(01):80-86

5 Ralston JD, Martin DP, Anderson ML, et al. Group health cooperative's transformation toward patient-centered access. Med Care Res Rev 2009;66(06):703-724

6 Garrido T, Meng D, Wang JJ, Palen TE, Kanter MH. Secure e-mailing between physicians and patients: transformational change in ambulatory care. J Ambul Care Manage 2014;37(03):211-218
7 Shimada SL, Hogan TP, Rao SR, et al. Patient-provider secure messaging in VA: variations in adoption and association with urgent care utilization. Med Care 2013;51(03, Suppl 1):S21-S28

8 Andreassen HK, Trondsen M, Kummervold PE, Gammon D, Hjortdahl P. Patients who use e-mediated communication with their doctor: new constructions of trust in the patient-doctor relationship. Qual Health Res 2006;16(02):238-248

9 Houston TK, Sands DZ, Jenckes MW, Ford DE. Experiences of patients who were early adopters of electronic communication with their physician: satisfaction, benefits, and concerns. Am J Manag Care 2004;10(09):601-608

10 Zhou YY, GarridoT, Chin HL, Wiesenthal AM, Liang LL. Patient access to an electronic health record with secure messaging: impact on primary care utilization. Am J Manag Care 2007;13(07):418-424

11 Zhou YY, Kanter MH, Wang JJ, Garrido T. Improved quality at Kaiser Permanente through e-mail between physicians and patients. Health Aff (Millwood) 2010;29(07):1370-1375

12 Harris LT, Haneuse SJ, Martin DP, Ralston JD. Diabetes quality of care and outpatient utilization associated with electronic patientprovider messaging: a cross-sectional analysis. Diabetes Care 2009;32(07):1182-1187

13 Goldzweig CL, Towfigh AA, Paige NM, et al. Systematic Review: Secure Messaging Between Providers and Patients, and Patients' Access to Their Own Medical Record. Evidence-based Synthesis Program (ESP) Center, West Los Angeles VA Medical Center. Washington, DC: Department of Veterans Affairs; 2012

14 Shimada SL, Allison JJ, Rosen AK, Feng H, Houston TK. Sustained use of patient portal features and improvements in diabetes physiological measures. J Med Internet Res 2016;18(07):e179

15 Beebe J. Rapid Assessment Process: An Introduction. Walnut Creek, CA: AltaMira Press; 2001

16 Haun JN, Lind JD, Shimada SL, et al. Evaluating user experiences of the secure messaging tool on the Veterans Affairs' patient portal system. J Med Internet Res 2014;16(03):e75

17 Haun JN, Patel NR, Lind JD, Antinori N. Large-scale survey findings inform patients' experiences in using secure messaging to engage in patient-provider communication and self-care management: a quantitative assessment. J Med Internet Res 2015;17(12):e282 